\title{
Influence of Thermal Insulation's and Phase Change Material's Insertion within a Partition Wall on the Energy Consumption of a Conditioned Room under Adjacent Local Periodical Temperature Effect
}

\author{
Nisrine Hanchi ${ }^{1,{ }^{*}, \text { Hamid } \text { Hamza }^{1} \text {, Rabiaa Idmoussa }}{ }^{1}$, Jawad Lahjomri ${ }^{1}$, and Abdelaziz Oubarra ${ }^{1}$ \\ ${ }^{1}$ Laboratory of Mechanics, Faculty of Sciences Ain Chock, Hassan II University of Casablanca, Morocco
}

\begin{abstract}
The aim of this work is to study the combined insertion effect of Phase Change Materials (PCM) and thermal insulation within a partition wall separating a conditioned room from an adjacent local which is under a periodic thermal activity. This is done by a comparative study with a reference wall under the same thermal conditions. The comparison criterion is the energy density transmitted to the local conditioned in established regime. The results show that the inclusion of thermal insulation and phase change material provides a significant reduction of energy consumption of the conditioned local; thereby a judicious choice of phase change material with thermal level and range melting temperature reduces further this reduction.
\end{abstract}

\section{Nomenclature}

$T$ Temperature (K)

$x$ Position within layer $(\mathrm{m})$

$c$ Specific heat $\left(\mathrm{J} \cdot \mathrm{Kg}^{-1} \mathrm{~K}^{-1}\right)$

$k$ Thermal Conductivity (W/m K)

$h$ Convective heat transfer coefficient $\left(\mathrm{W} . \mathrm{K}^{-1} \mathrm{~m}^{-2}\right)$

$L$ Wall thickness (m)

$f$ Liquid fraction of phase change material

$L_{f}$ Latent heat $(\mathrm{kJ} / \mathrm{kg})$

$\rho$ Density $\left(\mathrm{kg} / \mathrm{m}^{3}\right)$

$\alpha$ Thermal diffusivity $\left(\mathrm{m}^{2} / \mathrm{s}\right)$

\subsection{Indices}

$o / i$ Outside /Inside

$m$ Melting

\section{Introduction}

Currently, modern life is causing a huge problem of energy consumption. Climatic conditions generate a discomfort situation, which requires the increasing use of air conditioning systems.

There are several techniques to reduce the use of air-conditioning systems and improve the energy efficiency of buildings. Among the proposed solutions: insulation of walls and roofs [1], use of light colours on external surfaces [2] and energy storage devices in the building structure $[3,4,5]$. The last technique uses frequently phase change materials (PCM). Phase change material is known by its ability to store more energy and temperature fluctuations [6]. The investigation of PCM is made for the case of conditioned local $[7,8,9]$ and non-conditioned local [10]. Criteria of these works are the daily and annually energy per unit area $[1,8]$ or the flux density transmitted to the local $[7,11]$.

In the case of conditioned premises, the results of the various studies have shown that the insertion of thermal insulation or phase change materials is advantageous and reduces the energy consumption involved in these premises.

The aim of our study is to evaluate the simultaneous insertion effect of thermal insulation and phase change materials within a partition wall on the reduction of energy consumption. The partition wall separates two locals. The conditioned one is considered at constant temperature and corresponds to comfort temperature. The adjacent local is subject to a periodical thermal activity.

\section{Illustration of problem}

The reference partition wall is shown in Figure 1. It is a structure of total thickness $L$, consisting of concrete, subjected to two different thermal boundary conditions: constant temperature corresponding to the conditioned room comfort temperature $T_{i}$ and a sinusoidal temperature $T_{o}$ relative to the adjacent local. 


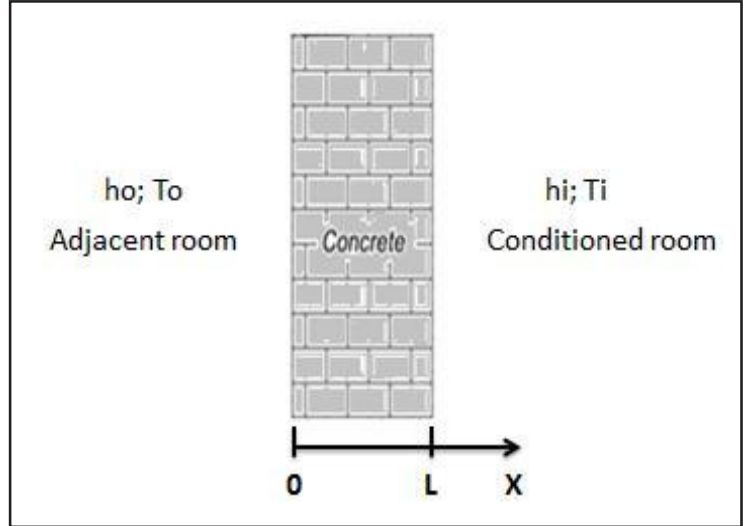

Fig. 1. Basic wall

The integration of phase change material and insulation, within the partition wall, is implemented without changing the basic structure and leads to two configurations as schematized in Figures 2 and 3 with $e_{1}=e_{2}=e_{3}=e_{4}=3 \mathrm{~cm}$ and $e_{5}=18 \mathrm{~cm}$.

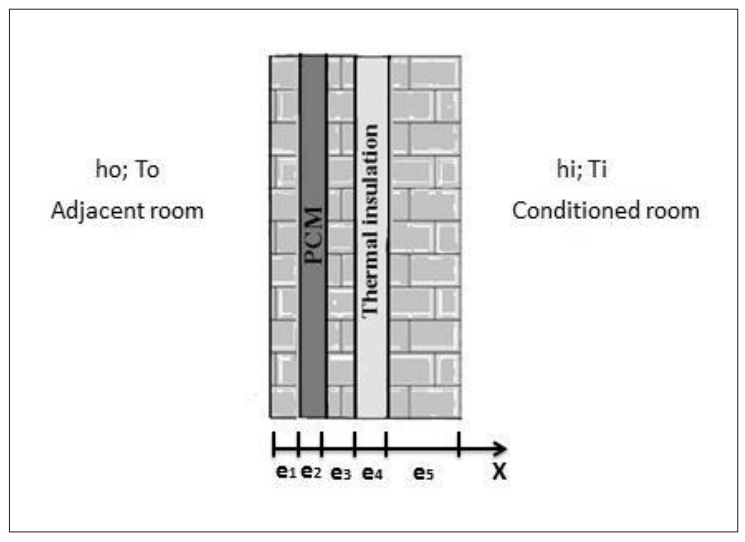

Fig. 2. Partition wall provided with phase change material and thermal insulation.

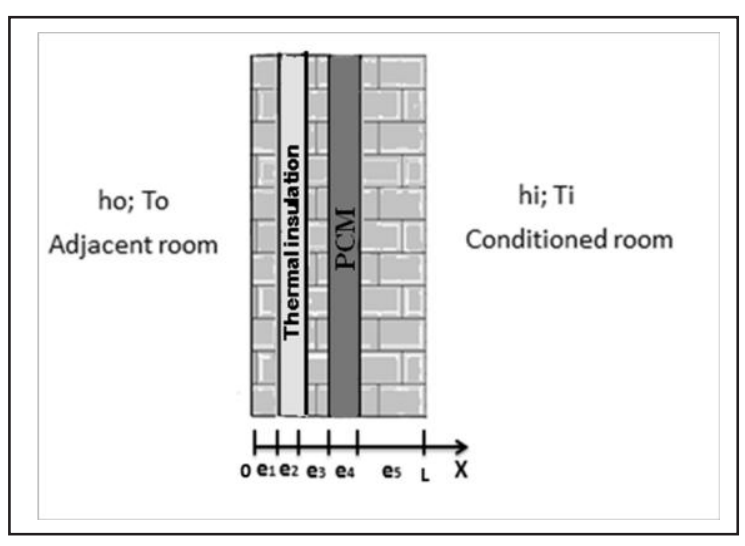

Fig. 3. Partition wall provided with thermal insulation and phase change material.

\section{Analysis and modelling}

The thermal behaviour of the multilayer wall system is given by the equations below. The equation 1 is applicable to the concrete and the insulation, while the equations 2 and 3 concern the phase change material, according to the enthalpy method. These equations are coupled with the continuity of temperature and flux at the different interfaces (equations 4 and 5) and are associated with the boundary conditions ( 6,7 and 8 ).

- Concrete and insulation (subscript 1):

$\frac{\partial T_{1}}{\partial t}=\alpha_{1} \frac{\partial^{2} T_{1}}{\partial x^{2}}$

- PCM (subscript p):

$\rho_{p} c_{p} \frac{\partial T_{p}}{\partial t}+\rho_{p} L_{f} \frac{\partial f}{\partial t}=k_{p} \frac{\partial^{2} T_{p}}{\partial x^{2}}$

Such as: $f$ is the liquid fraction defined by:

$$
\left\{\begin{array}{ccc}
f=0 & \text { if } & T_{p}<T_{m} \\
0<f<1 & \text { if } & T_{p}=T_{m} \\
f=1 & \text { if } & T_{p}>T_{m}
\end{array}\right.
$$

$T_{m}$ is the melting temperature, and $L_{f}$ the heat latent.

- Interfaces between concrete, phase change material and insulation :

$\left(T_{i}\right)_{i / i+1}=\left(T_{i+1}\right)_{i / i+1}$

$-\left.k_{i} \frac{\partial T_{i}}{\partial x}\right|_{i / i+1}=-\left.k_{i+1} \frac{\partial T_{i+1}}{\partial x}\right|_{i / i+1}$

- $x=0$ (Left side of partition wall):

$-\left.k_{1} \frac{\partial T_{1}}{\partial x}\right|_{x=0}=h_{o}\left(T_{o}-\left.T_{1}\right|_{x=0}\right)$

- $x=L$ ( Right side of partition wall):

$-\left.k_{1} \frac{\partial T_{1}}{\partial x}\right|_{x=L}=h_{i}\left(\left.T_{1}\right|_{x=L}-T_{i}\right)$

$T_{i}$ is the temperature of conditioned local, kept constant for whole study, while $T_{o}$ is the local adjacent temperature, evolving between the extremes values $T_{\min }$ and $T_{\max }$ according to the sinusoidal law given by:

$T_{o}=\bar{T}_{o}+\Delta T_{o} \cdot \sin (\omega . t)$

Where $\overline{T_{o}}=\frac{\left(T_{\max +} T_{\min }\right)}{2}$ and $\Delta T_{o}=\frac{\left(T_{\max }-T_{\min }\right)}{2}$ are respectively the average temperature value and the amplitude, while $\omega$ is the pulsation. This parameter is related to the daily period of the adjacent room temperature sinusoidal oscillations. 
The system of previous equations associated to the boundary and interfaces conditions has been solved by a scheme with implicit finite differences. This scheme is unconditionally stable which leads to a tridiagonal matrix system solved by Thomas algorithm. This resolution provides the evolution of temperature profile at each point of the wall. Choice of step time $\Delta t$ and space $\Delta x$ is a result of a consensus between computational time and accuracy.

\section{Validation of numerical solution}

Before presenting the numerical results the multilayer wall, provided with phase change material and thermal insulation, the numerical code is validated by comparison with analytical solution available in the literature relative to classic problem of Newman [12]. A phase change material is initially at the melting temperature $T_{i}=T_{m}$ in a semi-infinite rectangular geometry with a uniform cross-section. The surface is maintained at a temperature $T_{e}>T_{m}$ causing liquefaction of phase change material. The position of the solid-liquid interface as a function of time is calculated by the numerical code and compared with its theoretical position given by the function $y(\tau)=2 \eta \sqrt{\tau}$, where $\eta$ is a constant determined by solving the equation below:

$$
\eta \exp \left(\eta^{2}\right) \cdot \operatorname{erf}(\eta)=\frac{C_{l}}{L_{f} \sqrt{\pi}}\left(T_{e}-T_{m}\right)
$$

The results of the comparison between the numerical and analytical solutions are shown in Figure 4.

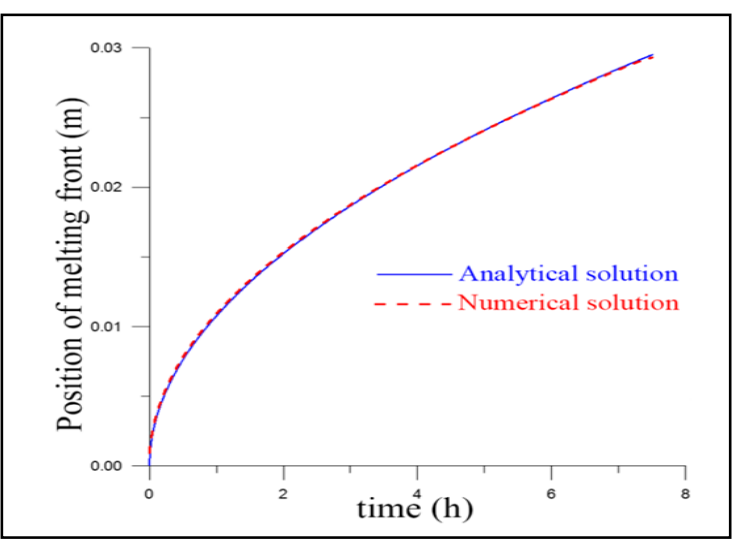

Fig.4. Position of melting front in function of time for Newman problem.

\section{Results and discussion}

We have chosen to keep the room considered conditioned at two comfort temperatures $T_{i}=20^{\circ} \mathrm{C}$ and $T_{i}=18^{\circ} \mathrm{C}$, while the adjacent room is considered at temperature varying sinusoidally.

Phase change materials selected are those with melting temperatures $T_{m}=19^{\circ} \mathrm{C}$ and $T_{m}=21^{\circ} \mathrm{C}$, while the thermal insulation is the EPS. The thermo physical properties of the phase change material, thermal insulation and concrete are summarized in Table 1.

Table 1.Physical properties of wall's materials.

\begin{tabular}{|c|c|c|c|c|c|c|}
\hline & $\begin{array}{c}\text { Melting } \\
\text { temperature } \\
\mathbf{T}_{\mathrm{f}}\left({ }^{\circ} \mathrm{C}\right) \\
\end{array}$ & $\begin{array}{c}\text { Latent heat } \\
\mathbf{L}_{\mathrm{f}}(\mathrm{kJ} / \mathbf{k g})\end{array}$ & $\begin{array}{c}\text { Thermal } \\
\text { Conductivity } \\
\text { K (W/m K) }\end{array}$ & $\begin{array}{l}\text { Specific heat } \\
\text { c }(\mathrm{kJ} / \mathrm{kg} \mathrm{K})\end{array}$ & $\begin{array}{c}\text { Density } \\
\rho\left(\mathrm{kg} / \mathrm{m}^{3}\right)\end{array}$ & $\begin{array}{c}\text { Thermal } \\
\text { diffusivity } \\
\alpha\left(\mathbf{m}^{2} / \mathbf{s}\right)\end{array}$ \\
\hline Concrete & - & - & 1.730 & 0.840 & 2400 & $8.5810^{-7}$ \\
\hline $\begin{array}{c}\text { Insulation } \\
\text { (EPS)[1] }\end{array}$ & - & - & 0.04 & 1.400 & 15 & $1.9010^{-6}$ \\
\hline \multirow[t]{2}{*}{ PCMs } & 19 [13] & 160 & 0.43 & 1.90 & 1520 & $1.4910^{-7}$ \\
\hline & $21[13]$ & 144 & $\begin{array}{l}0.7(\mathrm{l}) \\
0.5(\mathrm{~s})\end{array}$ & 3.6 & 1380 & $\begin{array}{l}1.41 \quad 10^{-7}(\mathrm{l}) \\
1.01 \quad 10^{-7}(\mathrm{~s})\end{array}$ \\
\hline
\end{tabular}

In order to apprehend the effect of melting range of PCM, we have introduced a melting factor parameter $\varepsilon$ taking values from $1 \%$ to $3 \%$. The merge interval $\left(T_{m_{1}}, T_{m_{2}}\right)$ is expressed in terms of the theoretical melting temperature $T_{m}$ according to:

$\left\{\begin{array}{l}T_{m_{1}}=T_{m}-\left(\varepsilon * 0.01 * T_{m}\right) \\ T_{m_{2}}=T_{m}+\left(\varepsilon * 0.01 * T_{m}\right)\end{array}\right.$

In this study, the insertion of PCM and thermal insulation is done by two ways combined and inverted: Concrete-PCM-Concrete-Insulation-Concrete (CPCIC) and Concrete-Insulation-Concrete-PCM-Concrete (CICPC). The combinations insertion effects are estimated by the relative deviation of energy $\sigma$ transmitted toward the partitions wall, comparatively to that corresponding to the reference wall. This parameter is deduced from the internal daily energy density $\phi$, transmitted to the conditioned local in established periodic regime according to :

$\sigma=\left[\frac{\left(\varphi_{\text {Daily }}^{\text {Wall with PCM } \text { and insulation }}-\varphi_{\text {Daily }}^{\text {Reference wall }}\right)}{\varphi_{\text {Daily }}^{\text {Reference wall }}}\right] \times 100$ 


$$
\varphi=\int_{\text {daily }} h_{i}\left(T_{x=L}-T_{i}\right) \mathrm{dt}
$$

For the case illustrated in Figure 2, where the PCM is placed before the insulation, we calculated the relative deviation, once for the PCM with the melting temperature $\left(T_{m}=19^{\circ} \mathrm{C}\right)$ and another time with the PCM with $\left(T_{m}=21^{\circ} \mathrm{C}\right)$. This is done with the values from 1 to 3 of the melting parameter for these two PCMs.

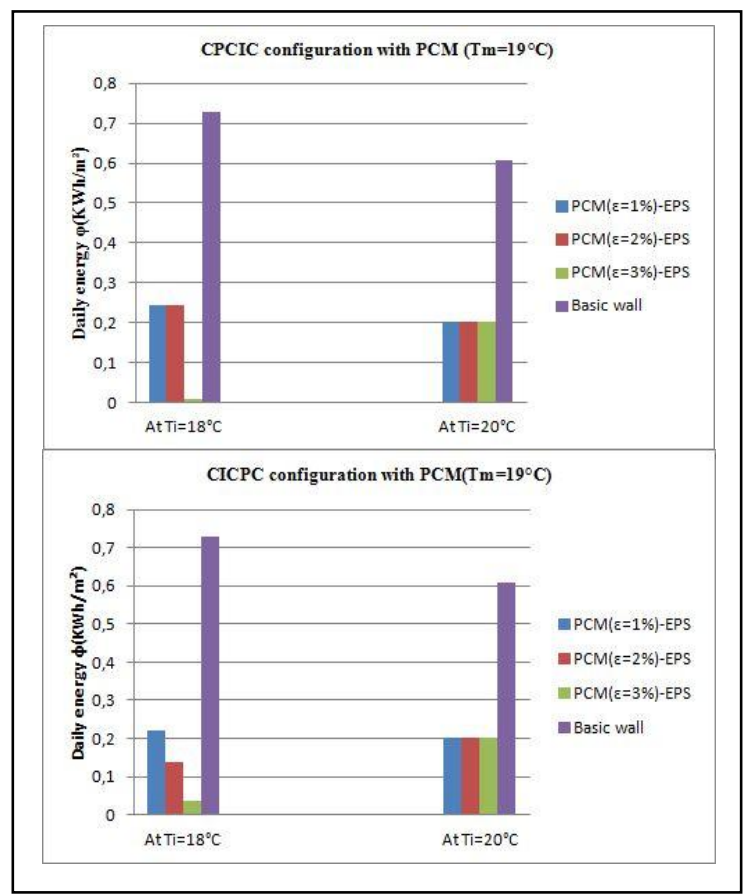

Fig. 5. Comparison of daily energy for the two configurations with PCM $\left(T_{m}=19^{\circ} \mathrm{C}\right)$ at two comfort temperatures.
Values of daily energy for the two PCMs and comfort temperatures are reported in Figures 5 and 6, whereas Table 2 and Figure 7 illustrate the corresponding relative deviation parameter $\sigma$. This leads to a comparison of daily energy for the two combinations of PCM and insulation (CPCIC and CICPC).

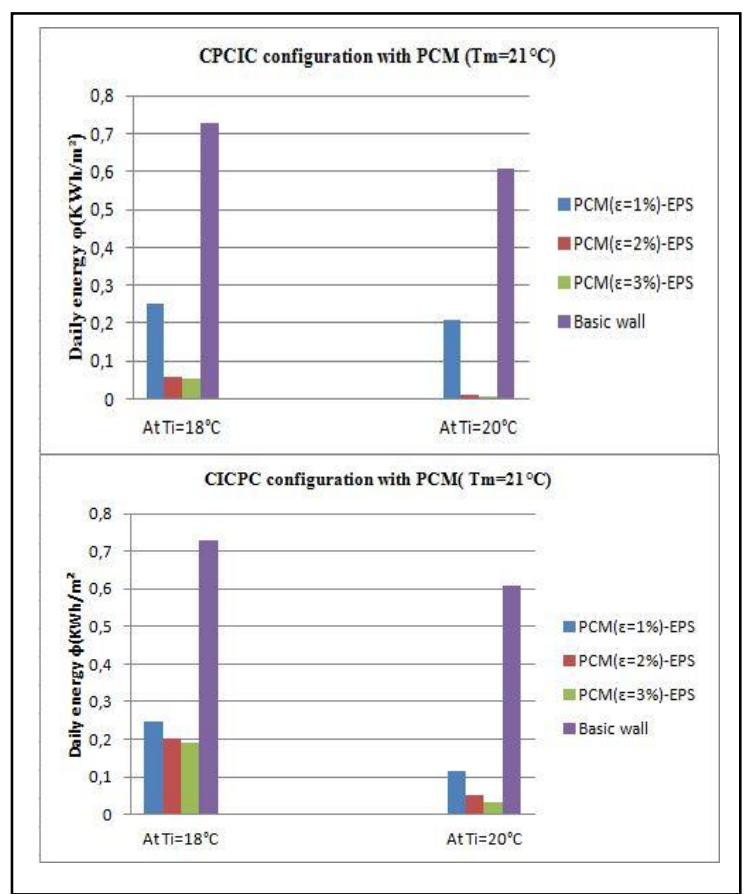

Fig.6. Comparison of daily energy for the two configurations with PCM $\left(T_{m}=21^{\circ} \mathrm{C}\right)$ at two comfort temperatures.

Table 2.Relative deviation of energy at the two comfort temperatures for the two combinations.

\begin{tabular}{|c|c|c|c|c|c|}
\hline At $\mathrm{Ti}=20^{\circ} \mathrm{C}$ & & & $1 \%$ & $2 \%$ & $3 \%$ \\
\hline \multirow{4}{*}{$\sigma(\%)$} & \multirow[b]{2}{*}{ CPCIC } & $\begin{array}{c}\mathrm{PCM} \\
\left(\mathrm{Tm}=19^{\circ} \mathrm{C}\right)\end{array}$ & $-66.5 \%$ & $-66.5 \%$ & $-66.5 \%$ \\
\hline & & $\begin{array}{c}\mathrm{PCM} \\
\left(\mathrm{Tm}=21^{\circ} \mathrm{C}\right)\end{array}$ & $-65.71 \%$ & $-97.85 \%$ & $-98.62 \%$ \\
\hline & \multirow{2}{*}{ CICPC } & $\begin{array}{c}\mathrm{PCM} \\
\left(\mathrm{Tm}=19^{\circ} \mathrm{C}\right)\end{array}$ & $-66.50 \%$ & $-66.50 \%$ & $-66.50 \%$ \\
\hline & & $\begin{array}{c}\text { PCM } \\
\left(\mathrm{Tm}=21^{\circ} \mathrm{C}\right)\end{array}$ & $-80.84 \%$ & $-91.81 \%$ & $-94.71 \%$ \\
\hline At $\mathrm{Ti}=18^{\circ} \mathrm{C}$ & & & $1 \%$ & $2 \%$ & $3 \%$ \\
\hline \multirow{4}{*}{$\sigma(\%)$} & \multirow[t]{2}{*}{ CPCIC } & $\begin{array}{c}\mathrm{PCM} \\
\left(\mathrm{Tm}=19^{\circ} \mathrm{C}\right)\end{array}$ & $-66.49 \%$ & $-66.49 \%$ & $-98.65 \%$ \\
\hline & & $\begin{array}{c}\mathrm{PCM} \\
\left(\mathrm{Tm}=21^{\circ} \mathrm{C}\right)\end{array}$ & $-65.71 \%$ & $-91.91 \%$ & $-92.54 \%$ \\
\hline & \multirow{2}{*}{ CICPC } & $\begin{array}{c}\mathrm{PCM} \\
\left(\mathrm{Tm}=19^{\circ} \mathrm{C}\right) \\
\end{array}$ & $-69.67 \%$ & $-81.25 \%$ & $-95 \%$ \\
\hline & & $\begin{array}{c}\mathrm{PCM} \\
\left(\mathrm{Tm}=21^{\circ} \mathrm{C}\right)\end{array}$ & $-66.22 \%$ & $-72.06 \%$ & $-73.97 \%$ \\
\hline
\end{tabular}


Results reported on Table 2 and Figures (5, 6 and 7) show a large reduction of energy transmitted to the conditioned local. These reductions depend on comfort temperature, melting temperature and range melting factor.

In the case of comfort temperature $T_{i}=20^{\circ} \mathrm{C}$, we note that the PCM $\left(T_{m}=19^{\circ} \mathrm{C}\right)$ generates practically the same behaviour of the partition wall for all values of the melting factor and for both configurations. Relative deviation of energy transmitted to the configurations remains fixed while varying melting factor parameter from 1 to 3 .

For CPCIC configuration and for this comfort temperature, the effect of phase change material which its melting temperature is equal to $21^{\circ} \mathrm{C}$, depends on the melting range parameter $\varepsilon$. For a value of $\varepsilon$ equal to 1 , the relative deviation of energy transmitted is the same as for the previous PCM, while high reduction of energy transmitted to the conditioned local is associated to the other values of $\varepsilon$.

Thus, for this case of thermal comfort, the best results are associated to phase change material having melting temperature equal to $\left(T_{m}=21^{\circ} \mathrm{C}\right)$ with melting factor parameter $\varepsilon$ equal to 2 and 3 .

In the other case of comfort temperature $T_{i}=18^{\circ} \mathrm{C}$, we remark that the daily energy for the PCM $\left(T_{m}=19^{\circ} \mathrm{C}\right)$ is the same for $\varepsilon$ equal to 1 and 2 and it decreases at $\varepsilon$ equal to 3 for CPCIC. For the CICPC configuration the energy is reduced respectively according to the value of $\varepsilon$ from 1 to 3. For $\operatorname{PCM}\left(\left(T_{m}=21^{\circ} \mathrm{C}\right)\right.$, the reduction is noted at $\varepsilon$ equal to 2 and 3 for both combinations. However, the CPCIC is rather better. Finally, for this comfort temperature, melting factor parameter equal to 1 leads to the same energy transmitted for the two phase change materials and the two configurations.

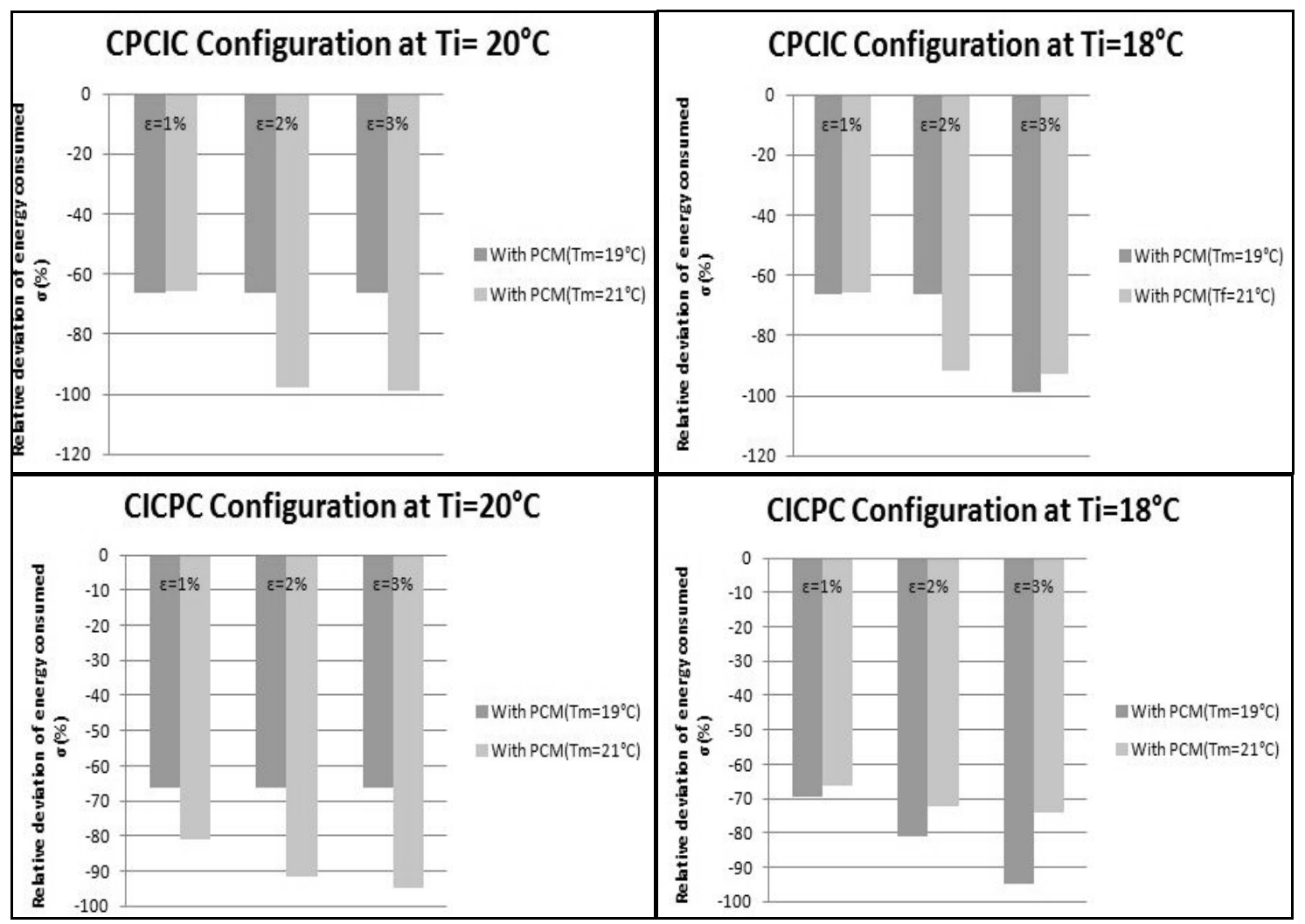

Fig.7. Histograms of both Configurations with PCMs $\left(T_{m}=19 ; 21^{\circ} \mathrm{C}\right)$ at $T_{i}=20^{\circ} \mathrm{C}$ and $18^{\circ} \mathrm{C}$.

\section{Conclusion}

This study deals with the insertion effect of thermal insulation and phase change material within a conventional partition wall. The various configurations are compared under the same thermal conditions corresponding to a local conditioned and a second whose temperature evolves periodically.

Based on a numerical code and the energy consumption as criterion, the results show that the insertion of the thermal insulation and the phase change material reduces significantly the energy consumption. The phase change material reduces further this consumption if level and range melting temperature are 
appropriate. The most suitable phase change material is that of a melting temperature slightly greater than a comfort temperature, associated with an adequate melting range.

The first author thanks the French - Maghreb project PHC (Volubilis side) for the training period in the University of Lorraine.

\section{References}

1. G. Barrios, G. Huels, J. Rojas, Applied Thermal Engineering, 40 (2012)

2. A.D. Granja, L.C. Labakiny, Int. J. Energy Res, 27 (2003)

3. A.L.S. Chan, T.T. Chow, Applied Energy, 107 (2013)

4. M. Pomianowski, P. Heiselberg, Y. Zhang, Energy and Buildings, 67 (2013)

5. N. Soares, J.J. Costa, A.R. Gaspar, V. Santos, Energy and Buildings, 59 (2013)

6. F.Kuznik, Energy and building, 40 (2008)

7. M. Izquierdo-Barrientos, J. Belmonte, D. Rodríguez- Sánchez, A. Molina, J. AlmendrosIbảnez, Applied Thermal Engineering, 47 (2012)

8. H. Hamza, N. Hanchi, B. Abouelkhayrat, J. Lahjomri, A. Oubarra, Thermal Science and Engineering Applications, 8 (2016)

9. N. Hanchi, H. Hamza, J.Lahjomri, A. Oubarra, Energy Procedia,139 (2017)

10. B. M. Diaconu, Energy and Buildings, 43 (2011)

11. B. Abouelkhayrat, H. Hamza, J. Lahjomri, A. Oubarra, Energy and Power Engineering, 5 (2013)

12. V. Alexiades, A.D. Solomon, (Hemisphere Publishing Corporation, Washington, USA ,1993)

13. P. Tatsidjodoung, N. L. Pierrès, L. Luo, Renewable and Sustainable Energy Reviews, 18 (2013) 